Editorial

\title{
Pharmacy (ISSN 2226-4787) —A Journal of Pharmacy Education and Practice
}

\author{
Keith A. Wilson * and Yvonne Perrie \\ Aston Pharmacy School, School of Life and Health Sciences, Aston University, Aston Triangle, \\ Birmingham, B4 7ET, UK; E-Mail: y.perrie@aston.ac.uk \\ * Author to whom correspondence should be addressed; E-Mail: k.a.wilson@aston.ac.uk; \\ Tel.: +44-1212-044041; Fax: +44-0121-204-4187.
}

Received: 1 February 2013 / Accepted: 1 February 2013 / Published: 22 February 2013

Pharmacy (ISSN 2226-4787) — A journal of pharmacy education and practice is an international scientific open access journal on pharmacy education and practice, and is published by MDPI online quarterly.

The practice of pharmacy is changing at an unprecedented rate as the profession moves from a focus upon preparation and supply of medicines to a clinical patient-facing role. While an understanding of the science related to medicines remains core to pharmacy education, the changes in practice are driving changes to the traditional methods of pharmacy education. This is reflected at an international level by major changes in the educational standards set by statutory regulators and by policy statements from bodies such as the World Health Organisation. These changes reflect an increasing trend to look at educational policy at a supra-national level, typified by the "Pharmine Project" led by the Association of European Faculties of Pharmacy.

The changing demands of pharmacy practice are leading to major developments from first level education to registration. Pharmacy education must develop new skill sets and this involves a re-definition of the boundaries between formal study and the workplace. There are arguably even greater challenges in the development of robust assessment methodologies that cover not only knowledge and skills but clinical and professional performance. However, even greater changes are to come in the development of the post-registration pharmacy workforce. This opens a whole series of exciting opportunities: a new level of collaboration between educators and practitioners, fundamental changes in the balance between formal education and work-based development and the need to explore new educational technologies.

There is much that pharmacy can learn from other professions and disciplines but equally there is an absolute need to develop robust processes appropriate to pharmacy. However, we believe that the key challenge will be in the interfacing of pharmacy education with practice. To address this and to 
promote further developments in pharmacy education, we have launched Pharmacy - a journal of pharmacy education and practice. Within this journal our aim is to support the dissemination of pharmacy and healthcare related educational research, with consideration of topics including development of learning tools and assessment strategies, curriculum design for healthcare education, the impact of education policy on programme design, interprofessional learning and supporting education across the health care community. This will ensure we are able to continually enhance the development of pharmacy education and meet the changing needs of students and practitioners and effectively exploit the ever increasing range of educational tools available. What is particularly exciting about this new journal is that it will embrace research both from an educational and practice perspective and provide a forum for understanding new and developing drivers of practice and their educational implications. For example, while the development of personalised medicines remains a key aspiration, there is limited motivation to develop personalised education. Could it be that the growing use of e-platforms for delivery of education may be depersonalising the educational process?

To help us achieve our aim with this journal, we have an excellent editorial board to advise us of all the exciting current and future trends in pharmacy education and in all sectors of pharmacy practice. We very much look forward to hearing all about the research going on across the world.

(C) 2013 by the authors; licensee MDPI, Basel, Switzerland. This article is an open access article distributed under the terms and conditions of the Creative Commons Attribution license (http://creativecommons.org/licenses/by/3.0/). 